\title{
PENGARUH CAMPURAN EKSTRAK AGLAIA HARMSIANA PERKINS DAN DYSOXYLUM ACUTANGULUM MIQ. (MELIACEAE) TERHADAP MORTALITAS DAN OVIPOSISI PLUTELLA XYLOSTELLA (L.) (LEPIDOPTERA: YPONOMEUTIDAE)
}

\author{
Lucy Yuswanti' dan Djoko Prijono ${ }^{2}$
}

\begin{abstract}
Effects of Mixtures of Aglaia harmsiana Perkins and Dysoxylum acutangulum Miq. (Meliaceae) Extracts on Mortality and Oviposition of Plutella xylostella (L.) (Lepidoptera: Yponomeutidae). This study was conducted to evaluate the effects of mixtures of extracts of Aglaia harmsiana seeds and Dysoxylum acutangulum leaf petioles on mortality and oviposition of Plutella xylostella (L.) (Lepidoptera: Yponomeutidae). The insecticidal activity of ethyl acetate fraction of $A$. harmsiana and $D$. acutanguhum extracts and their mixture (concentration ratio of $A h$ and $D a$ was 4:1) was evaluated against the third-instar larvae $P$. xylostella by a leaf-residue feeding method, and the oviposition-repellent effect of those extracts on adult $P$. xylostella was assessed by choice tests using broccoli seedlings. $\mathrm{LC}_{50}$ and $\mathrm{LC}_{35}$ of $A$. harmssiana extract against the third+fourth instar larvae were $0.054 \%$ and $0.129 \%$, respectively, those of D. acutangulum extract were $0.031 \%$ and $0.103 \%$, and those of the mixture of $A$. harmsiana and D. acutangulum extracts were $0.019 \%$ and $0.101 \%$. The test extract mixture was synergistic against the third+fourth instar larvae, both at $\mathrm{LC}_{30}$ and $\mathrm{LC}_{95}$ levels, with synergistic ratios of 3.3 and 1.1 , respectively. The treatments with $A$. harmsiana and $D$. acutangulum extracts and their mixture at concentrations of $0.06 \%-0.38 \%, 0,02 \%-0.3 \%$, and $0.02 \%=0.3 \%$, respectively, significantly reduced the number of eggs deposited by the females $P$. xylostella on broccoli seedlings, with oviposition inhibition indices of 0.30 $0.59,0.28-0.45$, and $0.45-0.70$. A. harmsiana extract at all concentrations tested was phytotoxic to broccoli seedlings, whereas $D$. acutangulum extract was not. Mixtures of $A$. harmsiana and $D$. acutangulum extracts were phytotoxic to broccoli seedlings at concentrations of $0.06-0.3 \%$. Thus, $A$. harmsiana extract or mixtures containing that extract should be used with caution and their phytotoxicity should be specifically tested on target crops before being used in the field.
\end{abstract}

Kata kunci: antioviposisi, fitotoksisitas, insektisida botani, Meliaceae, sinergisme

\section{PENDAHULUAN}

\section{Plutella xylostella (L.) (Lepidoptera:} Yponomeutidae) merupakan hama penting pada tanaman kubis-kubisan (Brassicaceae) yang bersifat kosmopolit (Kalshoven, 1981). Larva P. xylostella menimbulkan kerusakan dengan memakan daun dari permukaan bawah dan menyisakan lapisan epidermis atas sehingga meninggalkan gejala berupa jendela yang menerawang pada daun. Kerusakan yang ditimbulkan $P$, xylostella bersamaan dengan serangan Crocidolomia pavonana (F.) (Lepidoptera: Pyralidae) pada kubis dapat mencapai $100 \%$, terutama pada musim kemarau (Setiawati \& Sastrosiswojo, 1996).

Penerapan pengendalian hama terpadu (PHT) pada tanaman Brassicaceae telah dilakukan sejak 20 tahun yang lalu. Taktik pengendalian yang diterapkan untuk menanggulangi masalah hama $P$. xylostella mencakup pemanfaatan parasitoid Diadegma semiclausum (Hellen) (Hymenoptera: Ichneumonidae), penggunaan insektisida selektif berdasarkan ambang pengendalian $P$. xylostella (5 larva/10 tanaman), dan pengendalian secara kultur teknis (Setiawati \& Sastrosiswojo, 1996).

Salah satu kelompok insektisida selektif yang dapat digunakan untuk menunjang penerapan PHT kubis, termasuk terhadap hama $P$. xylostella, ialah insektisida botani. Kelompok insektisida ini bersifat ramah lingkungan karena umumnya tidak beracun terhadap musuh alami hama dan mudah terurai di alam. Selain itu, penggunaan sediaan insektisida botani yang mengandung campuran senyawa aktif dapat menekan timbulnya resistensi hama (Prijono, 1999).

Lebih dari 2400 jenis tumbuhan yang termasuk dalam 235 famili dilaporkan mengandung bahan pestisida (Grainge \& Ahmed, 1988). Beberapa genus tumbuhan yang memiliki prospek baik sebagai sumber insektisida botani antara lain Azadirachta, Aglaia, dan Dysaxylum. (Meliaceae) (Satasook et al., 1994, Schmutterer, 1995; Prijono et al., 2004).

Dua jenis tumbuhan famili Meliaceae yang berpotensi sebagai sumber insektisida botani ialah Aglaia harmsiana dan Dysoxylum acutangulum.

\footnotetext{
Alumnus Departemea Hama dan Penyakit Tumbuhan, Fakultas Pertanian Institut Pertanian Bogor

2 Dosen Departemen Hama dan Penyakit Tumbuhan, Fakultas Pertanian Institut Pertanian Bogor,

J. Kamper Kampus IPB Darmaga, Bogor
} 
Ekstrak aseton biji $A$. harmsiana dapat menghambat aktivitas makan dan perkembangan pradewasa $C$. pavonana (Dono \& Prijono, 1998; Prijono, 1998) serta menekan kemampuan reproduksi dan peletakan telur imago $C$. pavonana (Wiyantono et al., 2001). Berdasarkan penelitian lain, Prijono et al. (2001) melaporkan bahwa salah satu fraksi aktif kulit batang D. acutangulum memiliki aktivitas insektisida yang kuat terhadap larva $C$. pavonana dengan $\mathrm{LC}_{50} 6,6$ ppm. Gejala peracunan akibat perlakuan dengan ekstrak $D$. acutangulum dan fraksi aktifnya berupa kegagalan ganti kulit, dan larva umumnya mati menjelang atau pada saat ganti kulit (Prijono et al., 2004).

Untuk meningkatkan keefektifan dalam penggunaan insektisida, petani sering mencampur beberapa jenis insektisida. Di lain pihak, penggunaan insektisida dalam bentuk campuran sering disarankan untuk menunda timbulnya resistensi hama terhadap insektisida, mengendalikan beberapa jenis hama sekaligus, meningkatkan efisiensi aplikasi karena insektisida campuran digunakan pada dosis yang lebih rendah dibandingkan dengan dosis masing-masing komponennya secara terpisah, dan dapat mengurangi pengaruh samping terhadap organisme bukan sasaran dan lingkungan bila komponen campuran digunakan pada dosis yang lebih rendah (Prijono, 2002). Aktivitas insektisida campuran ekstrak $A$. harmsiana dan $D$, acutangulum sampai sekarang belum pernah diteliti.

Daya guna suatu insektisida akan bertambah bila insektisida tersebut juga memiliki sifat lain di samping mengakibatkan kematian hama, misalnya sifat antioviposisi (penghambat peletakan telur), karena sifat ini merupakan pertahanan garis depan dalam menangkal serangan hama. Pada serangga ordo Lepidoptera, tahapan pemilihan inang dalam proses peletakan telur sangat penting karena inang yang dipilih dapat mempengaruhi kelangsungan hidup larva keturunannya (Renwick \& Chew, 1994). Karena itu, sifat antioviposisi campuran ekstrak $A$. harmsiana dan D. acuiangulum juga perlu diteliti.

Penelitian ini bertujuan menentukan pengaruh campuran ekstrak biji $A$. harmsiana dan tangkai daun D. acutangulum terhadap mortalitas larva dan peletakan telur imago $P$, xylostella.

\section{METODE PENELITIAN}

\section{Perbanyakan Tanaman Pakan}

Pakan yang diberikan pada larva $P$. xylostella ialah daun brokoli (Brassica oleraceae L. var. italica, F1 Hybrid Broccoli 'Pilgrim'). Benih disemai pada nampan semai dengan 50 lubang tanam. Nampan semai tersebut diisi dengan medium tanam yang berasal dari sabut kelapa ('Green Leaf-200'). Pada setiap lubang tanam diletakkan satu benih dan satu butir pupuk majemuk pelepasan terkendali 'Dekastar'. Tanaman disiram dan dirawat setiap hari. Untuk medium pengujian aktivitas insektisida digunakan daun dari tanaman brokoli yang berumur 50-60 hari, sedangkan untuk pengujian antioviposisi digunakan bibit yang berumur sekitar 30 hari.

\section{Pemeliharaan Serangga Uji}

Serangga uji yang digunakan ialah larva instar ke-3 dan imago $P$. xylostella yang merupakan hasil perbanyakan di Laboratorium Fisiologi dan Toksikologi Serangga, Departemen Hama dan Penyakit Tumbuhan, Institut Pertanian Bogor. Larva instar awal dipelihara dalam kotak plastik ( $34 \mathrm{~cm}$ x 26 $\mathrm{cm} \times 7 \mathrm{~cm}$ ) dan diberi makan daun brokoli hingga mencapai fase pupa. Setelah pupa menjadi imago, imago dipindahkan ke dalam kurungan plastik (diameter $20 \mathrm{~cm}$, tinggi $35 \mathrm{~cm}$ ) dan diberi makan larutan madu $10 \%$ yang diserapkan pada kapas. Telur yang diletakkan pada daun brokoli digunakan untuk perbanyakan lebih lanjut atau dibiarkan menetas untuk memperoleh larva uji.

\section{Bahan Tumbuhan Sumber Ekstrak}

Bahan tumbuhan sumber ekstrak ialah biji $A$. harmsiana, yang diperoleh dari Kebun Raya Bogor, dan tangkai daun $D$, acutangulum, yang diperoleh dari Hutan Lindung Yan Lappa, Desa Tapos, Kecamatan Jasinga, Kabupaten Bogor.

\section{Ekstraksi}

Biji $A$. harmsiana dan tangkai daun $D$. acutangulum dikeringudarakan dan digiling secara terpisah dengan blender, hasil gilingan diayak dengan pengayak bermata $0,5 \mathrm{~mm}$, dan hasil ayakan diekstrak 
dengan metanol (perbandingan 1:10, w/v) dengan metode perendaman. Hasil rendaman disaring dan diuapkan dengan rotavapor pada suhu $50^{\circ} \mathrm{C}$ dan tekanan 337 mbar. Ekstrak yang dihasilkan dipartisi dalam campuran heksana dan metanol $95 \%$ dalam labu pernisah, dan fase metanolnya diuapkan dengan rotavapor seperti di atas. Fraksi metanol yang diperoleh dipartisi lebih lanjut dalam campuran etil asetat dan air, lalu fase etil asetatnya diambil dan diuapkan. Fraksi etil asetat yang diperoleh disimpan dalam lemari es pada suhu sekitar $4{ }^{\circ} \mathrm{C}$ sampai saat digunakan.

\section{Uji Toksisitas}

Fraksi etil asetat biji $A$. harmsiana dan tangkai daun $D$. acutangulum serta campurannya diuji pada enam taraf konsentrasi yang diharapkan dapat mematikan 20-95\% larva uji (berdasarkan uji pendahuluan). Perbandingan konsentrasi fraksi $A$. harmsiana dan D. acutanguhum dalam campuran ialah 4:1 (w/w). Ekstrak uji dicampur dengan campuran metanol dan aseton (3:1) serta pengemulsi alkil gliserol ftalat (Latron $77 \mathrm{~L}$ ), kemudian diencerkan dengan air sesuai konsentrasi yang diinginkan. Konsentrasi akhir campuran metanol dan aseton serta pengemulsi dalam suspensi masing-masing $1 \%$ dan $0,077 \%$

Metode pengujian yang digunakan ialah metode residu pada daun. Daun brokoli dipotong segi empat (4 cm x $4 \mathrm{~cm}$ ) kemudian dicelupkan dalam sediaan bahan uji selama 5 detik dan dikeringudarakan Daun kontrol dicelup dalam air yang mengandung campuran metanol dan aseton (3:1) $1 \%$ dan pengemulsi $0,077 \%$. Daun perlakuan atau daun kontrol diletakkan dalam cawan petri (diameter $10 \mathrm{~cm}$ ) yang dialasi tisu dan 15 larva instar ke-3 $P$. xylostella dimasukkan ke dalam cawan petri tersebut. Setiap perlakuan diulang lima kali. Setelah 48 jam, daun diganti dengan daun tanpa perlakuan kemudian larva diamati setiap hari sampai larva yang bertahan hidup mencapai fase pupa. Data mortalitas larva instar $3+4$ diolah dengan analisis probit (Finney, 1971).

\section{Uji Antioviposisi}

Pengujian sifat antioviposisi dilakukan dengan metode pilihan (bibit brokoli kontrol dan perlakuan diletakkan dalam satu kurungan). Setiap ekstrak tunggal dan campurannya diuji pada $\mathrm{LC}_{25}$, $\mathrm{LC}_{35}, \mathrm{LC}_{90}, \mathrm{LC}_{65}$, dan $\mathrm{LC}_{85}$ berdasarkan uji toksisitas. Sediaan ekstrak uji disiapkan dengan cara seperti pada uji toksisitas. Bibit brokoli yang berumur 1 bulan (memiliki empat daun) disemprot dengan sediaan ekstrak uji sebanyak $10 \mathrm{ml}$ per bibit. Bibit brokoli kontrol disemprot dengan air yang mengandung campuran metanol dan aseton serta pengemulsi seperti pada uji toksisitas. Bibit brokoli tersebut dan dua pasang imago $P$. xylostella yang berumur 3 hari dimasukkan ke dalam kurungan plastik beratap kasa (diameter $20 \mathrm{~cm}$, tinggi $35 \mathrm{~cm}$ ) dan dipelihara selama 3 hari dengan makanan larutan madu $10 \%$ yang diserapkan pada kapas. Jumlah telur yang diletakkan pada daun perlakuan dan daun kontrol dibandingkan dengan uji $t$-berpasangan. Indeks penghambatan oviposisi dihitung dengan rumus (Renwick \& Radke, 1988):

Indeks penghambatan oviposisi $=(K-P) /(K+P)$.

$\mathrm{K}$ dan $\mathrm{P}$ masing-masing jumlah telur yang diletakkan pada daun kontrol dan daun perlakuan.

\section{Analisis Toksisitas Campuran Ekstrak}

Perlakuan dengan ekstrak $A$. harmsiana mengakibatkan kematian larva tanpa penghambatan proses ganti kulit yang khas, sedangkan perlakuan dengan ekstrak D. aculanguhum mengakibatkan kematian yang terkait dengan kegagalan proses ganti kulit dan gangguan metamorfosis. Perbedaan gejala tersebut mencerminkan perbedaan cara kerja senyawa aktif dari kedua jenis ekstrak tersebut sehingga analisis toksisitas campuran kedua jenis ekstrak tersebut dilakukan berdasarkan model kerja bersama bebas (Finney, 1971; Robertson \& Smith, 1984).

Hasil analisis probit pada perlakuan ekstrak tunggal maupun campuran menghasilkan nilai $a$ (intersep), $b$ (slope), $\mathrm{LC}_{50}$, dan $\mathbf{L C}_{95}$. Untuk campuran, $\mathrm{LC}_{50}$ dan $\mathrm{LC}_{95}$ yang diperoleh disebut $\mathrm{LC}_{50}$ dan $L_{95}$ percobaan. $L_{S_{0}}$ dan $L_{95}$ harapan untuk campuran ditununkan berdasarkan model kerja bersama bebas (Finney, 1971; Robertson \& Smith, 1984):

$$
\mathrm{P}_{\mathrm{H}}=\mathrm{P}_{1}+\mathrm{P}_{2}-\mathrm{P}_{1} \cdot \mathrm{P}_{2}
$$

$\mathrm{P}_{\mathrm{H}}=$ proporsi mortalitas harapan $(0.5$ atau 0.95 untuk $\mathrm{LC}_{50}$ atau $\mathrm{LC}_{95}$ harapan campuran), $\mathrm{P}_{1}=$ proporsi mortalitas akibat perlakuan ekstrak $A$. harmsiana pada konsentrasi $\mathrm{c}_{1}$, dan $\mathrm{P}_{2}=$ proporsi mortalitas akibat perlakuan ekstrak $D$. acutangulum pada konsentrasi $\mathrm{c}_{2} ; \mathrm{c}_{1}+\mathrm{c}_{2}=\mathrm{LC}_{50}$ atau $\mathrm{LC}_{95}$ harapan campuran.

Prosedur rinci penghitungan $\mathrm{LC}_{50}$ dan $\mathrm{LC}_{95}$ harapan campuran mengikuti cara yang dikemukakan oleh Prijono (2002). Nisbah ko-toksisitas (NK, cotoxicity ratio) pada taraf $\mathrm{LC}_{90}$ dan $\mathrm{LC}_{95}$ dihitung dengan rumus: 
$\mathrm{NK}_{50}=\left(\mathrm{LC}_{50}\right.$ harapan $)\left(\mathrm{LC}_{50}\right.$ percobaan $)$

$\mathrm{NK}_{95}=\left(\mathrm{LC}_{95}\right.$ harapan $)\left(\mathrm{LC}_{95}\right.$ percobaan $)$

Jika NK >1, maka komponen campuran ekstrak bersifat sinergis; jika NK $<1$, maka komponen campuran ekstrak bersifat antagonis, dan jika NK $=1$, maka komponen campuran ekstrak bekerja bebas (Robertson \& Smith, 1984).

\section{HASIL DAN PEMBAHASAN}

\section{Toksisitas Bahan Uji terhadap Larva $P$. xylostella}

Larva $P$. xylostella yang mati akibat perlakuan dengan ekstrak tangkai daun (fraksi etil asetat) $D$. acutanguhum menunjukkan gejala kegagalan proses ganti kulit. Berbeda dengan pengaruh ekstrak $D$. acutangulum, fraksi etil asetat biji $A$. harmsiana mengakibatkan kematian tanpa gejala kegagalan proses ganti kulit yang khas. Pada perlakuan campuran, gejala yang teramati lebih menyerupai gejala yang disebabkan oleh ekstrak $A$. harmsiana. Hal ini disebabkan karena proporsi ekstrak $A$. harmsiana dalam campuran lebih tinggi (empat kali lipat) daripada ekstrak D. acutangulum dan interaksi antara senyawa aktif $A$. harmsiana dengan bagian sasaran tampaknya terjadi lebih awal.

Hasil analisis probit menunjukkan bahwa $\mathrm{LC}_{50}$ dan $\mathrm{LC}_{95}$ ekstrak campuran terhadap larva $P$. xylostella lebih rendah daripada $\mathrm{LC}_{50}$ dan $\mathrm{LC}_{95}$ kedua komponennya secara terpisah (Tabel 1). Hal ini menunjukkan bahwa penggunaan campuran fraksi etil asetat $A$. harmsiana dan D. aculangulum (4:1) akan lebih efisien dibandingkan dengan penggunaan ekstrak tunggal secara terpisah karena dalam campuran kedua komponen tersebut digunakan pada konsentrasi yang lebih rendah.

Campuran ekstrak A. harmsiana dan D. aculangulum bersifat sinergis terhadap larva $P$, xyloste/la, baik pada $\mathrm{LC}_{90}$ maupun $\mathrm{LC}_{95}$ dengan nisbah ko-toksisitas masing-masing 3,3 dan 1,1 (Tabel 2). Perbedaan nisbah ko-toksisitas pada taraf $L_{50}$ dan $L_{95}$ disebabkan karena garis regresi probit ekstrak $A$. harmsiana dan $D$. acutangulum tidak sejajar (kemiringan regresi $[b]$ berbeda nyata, Tabel 1), dan hal ini sesuai dengan hipotesis kerja bersama bebas (independent joint action).

Tabel I. Parameter toksisitas bahan uji terhadap larva $P$. xylosyella (berdasarkan mortalitas kumulatif instar $3+4$ )

\begin{tabular}{lccl}
\hline Ekstrak $^{a}$ & $b \pm \mathrm{GB}^{\mathrm{b}}$ & $\mathrm{LC}_{\text {so }}(\mathrm{SK} 95 \%)^{\mathrm{b}}(\%)$ & $\mathrm{LC}_{95}(\mathrm{SK} 95 \%)^{\mathrm{b}}(\%)$ \\
\hline A. harmsiana & $4,34 \pm 0,47$ & $0,054(0,039-0,064)$ & $0,129(0,106-0,187)$ \\
D. aculangulum & $3,11 \pm 0,37$ & $0,031(0,019-0,039)$ & $0,103(0,080-0,166)$ \\
Campuran & $2,26 \pm 0,29$ & $0,019(0,010-0,025)$ & $0,101(0,064-0,337)$
\end{tabular}

"Bahan yang diuji adalah fraksi etil asetatnya (lihat bagian Metode Penelitian).

${ }^{b} b=$ kemiringan garis regresi (slope), GB = galat baku, SK = selang kepercayaan.

Tabel 2. Sifat toksisitas campuran ekstrak A. harmsiana dan D. acutangulum terhadap larva P. xylostella

\begin{tabular}{lcccc}
\hline Taraf toksisitas & $\begin{array}{c}\text { LC percobaan } \\
(\%)\end{array}$ & $\begin{array}{c}\text { LC harapan } \\
(\%)\end{array}$ & $\begin{array}{c}\text { Nisbah } \\
\text { ko-toksisitas }\end{array}$ & $\begin{array}{c}\text { Sifat toksisitas } \\
\text { campuran }\end{array}$ \\
\hline LC $_{50}$ & 0,019 & 0,062 & 3,3 & Sinergistik \\
LC $_{95}$ & 0,101 & 0,111 & 1,1 & Sinergistik \\
\hline
\end{tabular}

${ }^{a}$ Diperoleh dari Tabel 1. 
Tabel 3. Pengaruh fraksi etil asetat $A$. harmsiana dan $D$. aculangulum serta campurannya terhadap oviposisi $P$. xylostella (metode pilihan)

\begin{tabular}{|c|c|c|c|c|c|}
\hline \multirow{2}{*}{ Ekstrak $^{a}$} & \multirow{2}{*}{$\begin{array}{c}\text { Konsentrasi } \\
(\%)\end{array}$} & \multicolumn{2}{|c|}{ Rataan jumlah telur $\pm \mathrm{SB}$} & \multirow{2}{*}{$p^{b}$} & \multirow{2}{*}{$\mathrm{IPO}^{\mathrm{C}}$} \\
\hline & & Perlakuan & Kontrol & & \\
\hline \multirow[t]{5}{*}{ A. harmsiana } & 0,06 & $20,8 \pm 13,1$ & $64,8 \pm 18,7$ & 0,004 & 0,51 \\
\hline & 0,08 & $39,0 \pm 38,9$ & $95,4 \pm 95,7$ & 0.103 & 0,42 \\
\hline & 0,13 & $41,8 \pm 38,7$ & $77,2 \pm 52,5$ & 0,001 & 0,30 \\
\hline & 0,19 & $31,0 \pm 21,3$ & $119,0 \pm 87,1$ & 0,056 & 0.59 \\
\hline & 0,38 & $29,8 \pm 40,4$ & $93,2 \pm 95,0$ & 0,062 & 0,51 \\
\hline \multirow[t]{5}{*}{ D. actutangu/um } & 0,02 & $66,8 \pm 56,8$ & $119,8 \pm 45,5$ & 0,009 & 0.28 \\
\hline & 0,03 & $58,0 \pm 40,0$ & $147,8 \pm 73,6$ & 0,051 & 0,44 \\
\hline & 0,06 & $62,2 \pm 35,6$ & $165,8 \pm 70,5$ & 0,017 & 0,45 \\
\hline & 0,10 & $52,8 \pm 25,2$ & $115,8 \pm 73,1$ & 0,073 & 0,37 \\
\hline & 0,30 & $44,0 \pm 36,4$ & $104,0 \pm 67,3$ & 0,002 & 0,40 \\
\hline \multirow[t]{5}{*}{ Campuran } & 0,02 & $27,4 \pm 14,9$ & $72,8 \pm 38,4$ & 0,031 & 0,45 \\
\hline & 0,03 & $13,2 \pm 2,9$ & $75,8 \pm 33,8$ & 0,016 & 0,70 \\
\hline & 0,06 & $19,4 \pm 18,9$ & $90,2 \pm 20,8$ & 0,004 & 0,64 \\
\hline & 0,10 & $20,4 \pm 23,4$ & $72,2 \pm 27,6$ & 0,024 & 0,56 \\
\hline & 0,30 & $20,4 \pm 10,8$ & $78,6 \pm 36,6$ & 0,024 & 0,59 \\
\hline
\end{tabular}

"Bahan yang diuji adalah fraksi etil asetatnya (lihat bagian Metode Penelitian)

${ }^{b}$ Nilai $P$ untuk perbedaan antara perlakuan dan kontrol menurut uji i-berpasangan.

${ }^{\mathrm{C}} \mathrm{IPO}=$ indeks penghambatan oviposisi.

\section{Aktivitas Antioviposisi Bahan Uji terhadap Imago P. xylostella}

Perlakuan fraksi etil asetat $A$. harmsiana dan D. acutangulum berpengaruh nyata terhadap peletakan telur $P$. xylostella, Jumlah telur yang diletakkan pada daun perlakuan lebih sedikit dibandingkan dengan kontrol dengan indeks penghambatan oviposisi (IPO) $0,30-0,59$ pada perlakuan $A$. harmsiana, 0,28 - 0,45

pada perlakuan $D$. acutangulum, dan $0,45-0,70$ pada perlakuan ekstrak campuran (Tabel 3). Pengaruh konsentrasi terhadap IPO tidak menunjukkan pola yang teratur. Hal ini mungkin disebabkan oleh keragaman perilaku imago betina $P$. xylostella yang digunakan atau keragaman kandungan stimuli pada bibit brokoli yang digunakan.

Fraksi etil asetat $A$. harmsiana ternyata fitotoksik terhadap bibit brokoli sedangkan fraksi etil asetat $D$, acutangulum tidak. Daun pada bibit yang disemprot dengan $A$. harmsiana awalnya melepuh, membentuk bercak, mengeriting, layu, dan pada akhir pengamatan daun tua maupun pucuk mengering dan mati. Pada perlakuan ekstrak D. acutangulum tidak ditemukan gejala tersebut. Pada perlakuan campuran, gejala fitotoksik teramati pada perlakuan konsentrasi $0,06 \%-0,3 \%$.

\section{Pembahasan Umum}

Fraksi etil asetat biji $A$. harmsiana dan tangkai daun $D$, acutangulum serta campuran kedua jenis ekstrak tersebut memiliki aktivitas insektisida yang kuat terhadap larva $P$. xylostella. Perlakuan dengan ekstrak A. harmsiana mengakibatkan penurunan mobilitas larva yang diduga akibat adanya penghambatan aktivitas makan dan/atau toksisitas intrinsik senyawa aktif $A$. harmsiana; selanjutnya bagian tubuh larva menghitam yang mencerminkan kematian jaringan, dan akhirnya larva mati.

Pada sejumlah spesies lain dari Aglaia, rokaglamida (golongan benzofuran) telah diketahui sebagai senyawa aktif utama yang bersifat insektisida (Proksch et al., 2001). Nugroho et al. (1997) telah mengisolasi dan mengidentifikasi satu senyawa 
glikosida turunan rokaglamida dari daun $A$. harmsiana, tetapi senyawa insektisida dari bagian biji belum pernah dilaporkan. Rokaglamida dan turunannya dilaporkan bersifat toksik atau menghambat pertumbuhan sel tumor tertentu (Proksch et al., 2001).

Tingkat aktivitas ekstrak D. acutangulum dan gejala peracunan yang teramati pada penelitian ini sesuai dengan laporan sebelumnya (Prijono et al., 2001, 2004). Gangguan terhadap proses ganti kulit mencerminkan bahwa senyawa aktif $D$. acutangulum bekerja dengan mengganggu sistem hormon yang mengendalikan proses tersebut. Proses ganti kulit pada serangga melibatkan sedikitnya tujuh jenis hormon, yaitu hormon protorasikotropik, hormon juvenil, ekdison, hormon pemicu ekdisis, hormon eklosi, bursikon, dan peptida kardioaktif Crustacea (Chapman, 1998). Untuk menentukan jenis hormon yang terpengaruh, perlu penelitian lebih lanjut.

atians to Senyawa aktif yang bersifat insektisida dari D. acutangulum belum pernah diidentifikasi. Nishizawa et al. (1983) telah mengisolasi senyawa (+)-8-hidroksi-kalamenena (golongan sesquiterpena fenol) dari biji $D$, acutangzulum dan $D$, alliacenum sebagai senyawa aktif racun ikan dan antibakteri. Dengan memperhatikan sifat penghambat perkembangan serangga dari ekstrak $D$. acutanguhum dan senyawa golongan terpenoid sebagai senyawa aktif utama dalam tumbuhan Meliaceae yang bersifat menghambat perkembangan serangga (Schmutterer, 1995) serta laporan Nishizawa et al. (1983), kemungkinan senyawa aktif dalam $D$. acutangulum berasal dari golongan terpenoid. Untuk membuktikan dugaan ini perlu penelitian lebih lanjut.

Selain bersifat insektisida terhadap larva $P$. xylostella, fraksi $A$. harmsiana dan $D$, acutangulum serta campurannya juga menghambat peletakan telur oleh imago betina $P$. xylostella. Penghambatan peletakan telur pada $P$. xylostella disebabkan karena komponen penghambat yang terdapat dalam fraksi etil asetat D. acutangulum dan A. harmsiana mampu mengatasi pengaruh faktor perangsang yang terdapat pada tanaman brokoli. Pada tanaman famili Brassicaceae, glukosinolat dan hasil hidrolisisnya dapat berperan sebagai perangsang peletakan telur (Renwick \& Chew, 1994).

Meskipun campuran ekstrak A. harmsiana dan D. acutangulum memiliki aktivitas insektisida dan antioviposisi yang lebih tinggi daripada ekstrak tunggal, kemanfaatan campuran tersebut tampaknya dibatasi oleh sifat fitotoksisitasnya. Sasaran senyawa aktif $A$. harmsiana mungkin tidak terbatas hanya terdapat dalam tubuh serangga sehingga senyawa tersebut juga dapat meracuni sel tumbuhan. Namun demikian, sifat fitotoksik tersebut mungkin dapat dikurangi dengan menurunkan proporsi ekstrak $A$. harmsiana dalam campuran atau memurnikan ekstrak tersebut. Selain itu, ekstrak tersebut mungkin masih dapat digunakan pada tanaman lain yang lebih toleran dibandingkan dengan brokoli. Untuk itu, pengujian fitotoksisitas perlu dilakukan secara spesifik pada tanaman inang hama sasaran.

\section{SIMPULAN}

Campuran fraksi etil asetat biji $A$. harmsiana dan tangkai daun $D$. acutangulum bersifat sinergis terhadap larva instar $3+4$ P. xylostella pada taraf $\mathrm{LC}_{50}$ maupun $L_{95}$ dengan nisbah ko-toksisitas masingmasing 3,3 dan 1,1. Aktivitas antioviposisi campuran tersebut terhadap imago betina $P$. xylostella juga lebih besar dibandingkan dengan ekstrak tunggalnya pada konsentrasi yang sama. Namun, campuran tersebut pada konsentrasi $0,06 \%-0,3 \%$ fitotoksik pada bibit brokoli. Fraksi etil asetat A. harmsiana fitotoksik pada semua taraf konsentrasi uji $(0,06 \%-0,38 \%)$, sedangkan fraksi etil asetat $D$, acutangulum tidak. Untuk menghindari terjadinya fitotoksisitas pada tanaman brokoli, proporsi ekstrak $A$. harmsiana dalam campuran perlu dikurangi atau ekstrak $D$. acutangulum digunakan secara tunggal.

\section{SANWACANA}

Percobaan ini merupakan bagian dari penelitian yang dibiayai RUT VIII (2001-2002). Penulis mengucapkan terima kasih kepada Pimpinan Proyek RUT atas dukungan dananya. Ucapan terima kasih juga disampaikan kepada Sdr. Agus Sudrajat atas bantuan teknisnya.

\section{DAFTAR PUSTAKA}

Chapman, R. F, 1998. The Insects: Structure and Function. 4th ed. Cambridge University Press, Cambridge.

Dono, D. \& D. Prijono. 1998. Aktivitas insektisida ekstrak biji Aglaia harmsiana Perkins dan fraksinya terhadap larva Crocidolomia binotalis Zeller (Lepidoptera: Pyralidae). Bul. HPT 10: 19-28. 
Finney, D. J. 1971. Probit Analysis. 3rd ed. Cambridge University Press, Cambridge.

Grainge, M. \& S. Ahmed. 1998. Handbook of Plants with Pest Control Properties. John Wiley \& Sons, New York.

Kalshoven, L. G. E. 1981. The Pests of Crops in Indonesia. van der Laan PA, penerjemah. PT lchtiar Baru-van Hoeve, Jakarta. Terjemahan dari: De Plagen van de Cultuurgewassen in Indonesie.

Nishizawa, M., A. Inoue, S. Sastrapradja, \& Y. Hayashi. 1983. (+)-8 hydroxy-calamenene: a fish poison principle of Dysoxylum acutangulum and Dysoxylum alliaceum. Phytochemistry 22:2083-2085.

Nugroho, B. W., V. Güssregen, V. Wray, L. Witte, G. Bringmann, \& P. Proksch. 1997. Insecticidal rocaglamide derivatives from Aglaia elliptica and Aglaia harmsiana. Phytochemistry 34: 579-580.

Prijono, D. 1998. Insecticidal activity of meliaceous seed extracts against Crocidolomia binotalis Zeller (Lepidoptera : Pyralidae), Bul. HPT 10: $1-7$.

Prijono, D. 1999. Prospek dan strategi pemanfaatan insektisida alami dalam pengendalian hama terpadu. Hlm. 1-7 dalam: Bahan Pelatihan Pengembangan dan Pemanfaatan Insektisida Alami, Bogor, 9-13 Agustus 1999. РКРHT IPB, Bogor,

Prijono, D. 2002. Pengujian Keefektifan Campuran Insektisida: Pedoman bagi Pelaksana Pengujian Efikasi untuk Pendaftaran Pestisida. Jurusan HPT, IPB, Bogor.

Prijono, D., E. Syahputra, Sudarmo, B. W. Nugroho, \& P. Simanjuntak. 2001. Aktivitas lima jenis insektisida alami terhadap ulat krop kubis Crocidolomia binotalis Zeller. Hlm. 72-80 dalam: Sukartana, P. et al., ed. Prosiding Seminar Nasional III PEI: Pengelolaan Serangga yang Bijaksana Menuju Optimasi Produksi, Bogor, 6 November 2001. Perhimpunan Entomologi Indonesia Cabang Bogor, Bogor.

Prijono, D., J. L. Sudiar, Irmayetri, \& E. Suhaendah. 2004. Insecticidal effectiveness of extracts of forty three species of tropical plants against the cabbage head caterpillar, Crocidolomia pavonana (F.). Presented at 2004 Hawaii International Conference on Sciences, Honolulu, 15-18 January, 2004.

Proksch, P., R. Edrada, R. Ebel, I. F. Bohnenstengel, \& B. W. Nugroho. 2001. Chemistry and biological activity of rocaglamide derivatives and related compounds in Aglaia species (Meliaceae). Curr, Org, Chem. 5:923-938.

Renwick, J. A. A. \& C. D. Radke. 1988. Sensory cues in host selection for ovipotition by the cabbage butterfly, Pieris brassicae. J. Insect Physiol. 34: 251-257,

Renwick, J. A. A \& F. S. Chew. 1994. Oviposition behavior in Lepidoptera. Annu. Rev. Entomol. 39: $377-400$.

Robertson, J.L. \& K. C. Smith. 1984. Joint action of pyrethroids with organophoshorus and carbamate insecticides applied to western spruce budworm (Lepidoptera: Tortricidae). $J$. Econ. Entomol. 77: 16-22.

Satasook, C., M. B. Isman, F. Ishibashi, S. Medbury, P. Wiriyachitra, \& G. H. N. Towers. 1994. Insecticidal bioactivity of crude extracts of Aglaia species (Meliaceae). Biochem. System. Ecol. 22: 121-127.

Schmutterer, H., ed. 1995. The Neem Tree, Azadirachta indica $A$. Juss, and other Meliaceous Plants: Sources of Unique Natural Products for Integrated Pest Management, Medicine, Industry and Other Purposes. VCH, Weinheim.

Setiawati, W. \& S. Sastrosiswojo. 1996. Penerapan komponen teknologi pengendalian hama terpadu pada tanaman kubis di dataran tinggi dan dataran medium. Hlm. 347-353 dalam: Prosiding Seminar Ilmiah Nasional Komoditas Sayuran, Lembang, 24 Oktober 1995. Balai Penelitian Tanaman Sayuran, Lembang (Bandung).

Wiyantono, D. Prijono, \& S. Manuwoto. 2001. Bioaktivitas ekstrak biji Aglaia harmsiana terhadap ulat krop kubis Crocidolomia binotalis. J. Ilmu Pert. Indon. 10: 1-7. 